\title{
Testing of a Lightweight SiC Power Module for Avionic Applications
}

\author{
E. Gurpinar*, S. Lopez-Arevalo*, J. Li*, D. De ${ }^{*}$, A. Castellazzi*, L. Mills ${ }^{\dagger}$ \\ ${ }^{*}$ PEMC Group, The University of Nottingham, U.K., ${ }^{\dagger}$ Semelab Limited, U.K. \\ Email: emre.gurpinar@nottingham.ac.uk
}

Keywords: $\mathrm{SiC}$, silicon carbide, MOSFET, SiC power module, high-frequency inverter, three-phase inverter, avionic systems

\begin{abstract}
Functional and performance tests of a three-phase, two-level power module based on CREE $1.2 \mathrm{kV}$ SiC MOSFETs for avionic applications is presented in this paper. $\mathrm{SiC}$ devices have superior properties over conventional Si devices at high voltage operations and these properties make $\mathrm{SiC}$ devices attractive for avionic industry in order to reduce size of power electronic converters while maintaining high efficiency. This paper starts with a brief explanation of thermo-mechanical design approach of SiC power module. Thermo-mechanical design is followed by test setup and experimental results for different load and switching frequency conditions. The module is tested up to $540 \mathrm{~V}$ DC link voltage, $6 \mathrm{~kW}$ output power with $100 \mathrm{kHz}$ switching frequency. Experimental results show that the module can be successfully operated with high efficiency at high switching frequencies.
\end{abstract}

\section{Introduction}

Silicon carbide ( $\mathrm{SiC}$ ) has superior properties over silicon ( $\mathrm{Si}$ ), which has been the dominant semiconductor material for power semiconductor devices, that make $\mathrm{SiC}$ a potential candidate to replace $\mathrm{Si}$ for high voltage, high power applications. $\mathrm{SiC}$ has three times higher energy gap and seven times higher electric breakdown field that allow $\mathrm{SiC}$ to have higher voltage withstand capability. In addition to high voltage withstand capability, $\mathrm{SiC}$ has three times higher electron velocity than $\mathrm{Si}$, that leads to operate $\mathrm{SiC}$ at high switching frequencies [1-5]. High voltage and high switching capability of $\mathrm{SiC}$ resulted in commercially available active and passive power devices like MOSFET, normally on and off JFETs, BJT and Schottky diode at $1200 \mathrm{~V}$ from different manufacturers. It should be noted that due to high on-state resistance at high voltage applications ( $>1000 \mathrm{~V})$, Si MOSFET is considered impractical [6].

SiC devices has already drawn attention from avionic industry due to its high performance at high frequency, high power and high temperature applications [7]. In [8], switching performance and robustness of two 1200V SiC MOSFETs from different manufacturers are compared. Gate oxide reliability of SiC MOSFETs for more-electric-aircraft applications is discussed in [4]. Switching performance evaluation of Si and

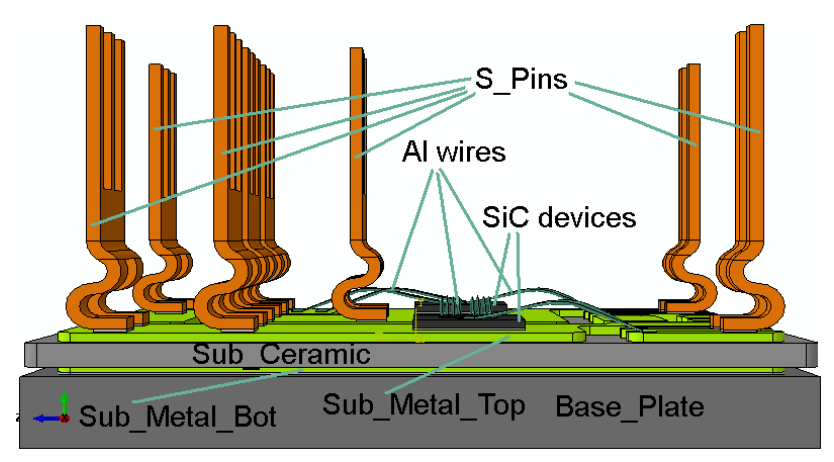

(a)

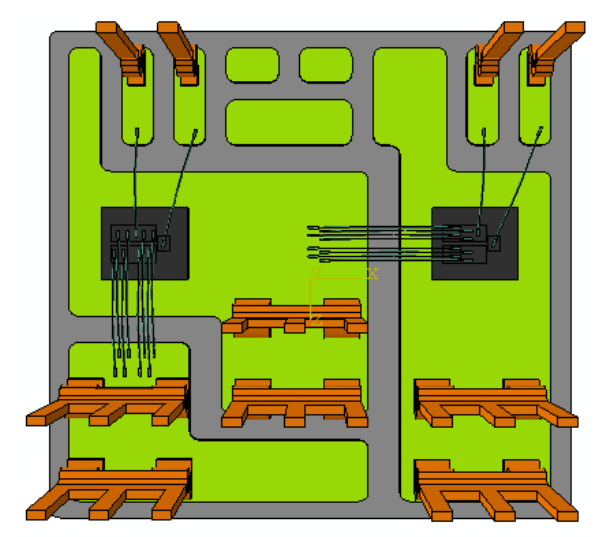

(b)

Figure 1: Half-bridge switch: (a) side view and (b) top view

$\mathrm{SiC}$ for avionic applications in [9] shows that $\mathrm{SiC}$ devices have ten times less switching losses in comparison to Si devices for given operating conditions.

Different $\mathrm{SiC}$ power modules have been designed and presented in literature $[7,10,11]$. A $1200 \mathrm{~V}, 800 \mathrm{~A} \mathrm{SiC}$ dual power module for electric vehicle applications, which incorporates twenty $80 \mathrm{~A} \mathrm{SiC} \mathrm{MOSFETs} \mathrm{and} \mathrm{twenty} \mathrm{50A} \mathrm{SiC} \mathrm{Schottky}$ diodes, is evaluated in [10]. The module shows the parallel operation capability of SiC MOSFETs and Schottky diodes with peak loading of $900 \mathrm{~A}, 600 \mathrm{~V} \mathrm{DC}$ bus. The results show that inverter losses can be reduced by $40 \%$ in comparison to $\mathrm{Si}$ IGBT module for most operating conditions; and for similar output current levels, experimental results show that $\mathrm{SiC}$ module switch four times faster than Si IGBT module. The reliability study of the module is presented in [12] and results 
show that $\mathrm{SiC}$ switches demonstrate high degree of stability in leakage current, on-state resistance, junction temperature and switching energy variation. In [11], a direct liquid cooled $\mathrm{SiC}$ power module is presented where direct liquid cooling provides better cooling performance of the module and enables exploitation of the SiC performance. Experimental results in this paper show that by using direct cooling and $\mathrm{SiC}$ devices, current density of the module can be increased at least three times and power losses can be reduced $50 \%$, in comparison to all-Si modules.

In this paper, a three-phase, two-level $\mathrm{SiC}$ power module based on CREE CPMF-1200-S080B Z-FET ${ }^{\mathrm{TM}}$ is presented. In section 2, thermo-mechanical design of half-bridge and power module is presented . Experimental setup, components and test strategy are presented in section 3 . Section 3 is followed by the experimental results of the module with different load, frequency and power conditions in section 4 .

\section{Design of Half-Bridge Switch and Power Module}

The overall design of the power module is based on integration of three individual half-bridge legs in a single package. Dimensions of each MOSFET die is $4.08 \times 4.08 \times 0.365 \mathrm{~mm}$ and the pin arrangement of each device has been designed to maximise the switching performance. Half-bridge design of the module is given in Figure 1.

SiC MOSFETs and all the pins are soldered onto the top metal substrate (Sub_Metal_Top), and the bottom metal substrate (Sub_Metal_Bot) is soldered on the base plate (Base_Plate). Thermo-mechanical analysis and simulation is mainly to investigate the effects of type and thickness of the substrate and base plate on the thermal and thermo-mechanical performance of the switch module. Therefore, all the solder joints are made of with eutectic Sn-3.5Ag solder and fixed to a constant thickness of $100 \mu \mathrm{m}$ and the $\mathrm{Al}$ wire-bonds are fixed to a constant diameter of $125 \mu \mathrm{m}$. Because the application does not target specifically high temperature applications, aluminium wire-bonds are used for interconnections to the device top-side.

For substrate, two types of substrates commonly used in power modules have been considered. The first one is $0.4 \mathrm{~mm}$ and $0.3 \mathrm{~mm}$ thick active brazed $\mathrm{Cu}$ on both sides of $1 \mathrm{~mm}$ or $0.635 \mathrm{~mm}$ thick AlN tile. The second one is $0.4 \mathrm{~mm}$ and $0.3 \mathrm{~mm}$ thick (or $0.3 \mathrm{~mm}$ and $0.2 \mathrm{~mm}$ ) active brazed $\mathrm{Cu}$ on both sides of $0.3 \mathrm{~mm}$ or $0.635 \mathrm{~mm}$ thick $\mathrm{Si}_{3} \mathrm{~N}_{4}$ tile. During the thermomechanical analysis, AlSiC-9 and AlSiC-12 composite base plates have been considered. According to thermo-mechanical results, $2 \mathrm{~mm}$ thick AlSiC-9 base plate and AlN based substrate with $0.635 \mathrm{~mm}$ AlN tile are selected for optimum design with respect to the provided loss mission profile of $\mathrm{SiC}$ switches. Assembled half bridge and power module are given in Figure $2 \mathrm{a}$ and $2 \mathrm{~b}$ respectively.

\section{Test Setup}

A flexible test setup has been designed in order to test five different modules that have been manufactured and the schematic and photo of the test setup are given in Figure 3 and 4 respectively. The power plane in the setup is connected to four electrolytic capacitors $(350 \mathrm{~V}, 3.3 \mathrm{mF}$ each) with discharge and balancing resistors $(47 \mathrm{k} \Omega$ each $)$, and the power plane is mounted on the $\mathrm{SiC}$ module power pins.

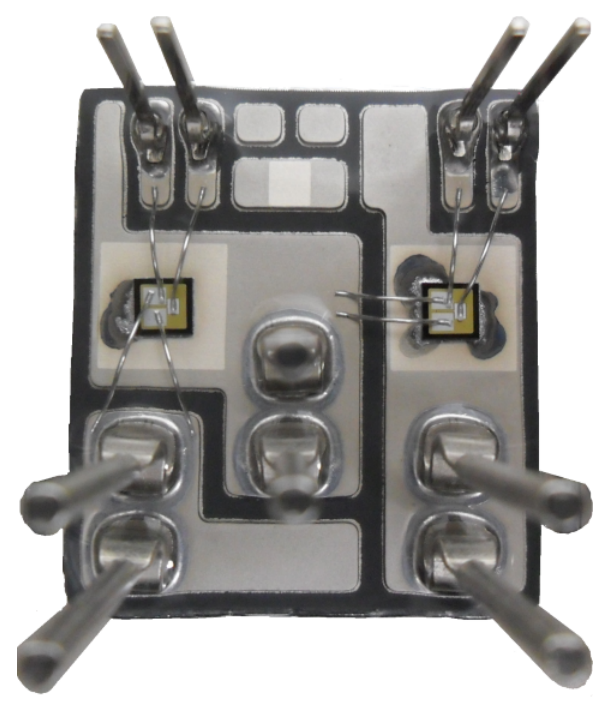

(a)

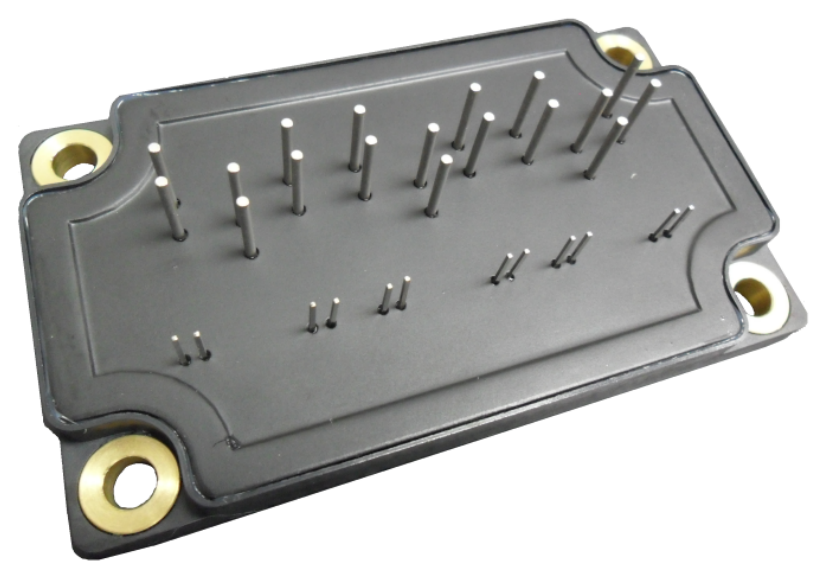

(b)

Figure 2: Lightweight SiC MOSFET module: (a) half bridge and (b) assembled module

The power converter is tested with open loop control at all times and the PWM drive signal for each device is generated by a DSP+FPGA control platform with appropriate dead-time values. PWM signals are transmitted to gate driver board, which is mounted on the $\mathrm{SiC}$ module gate pins, through fibre optic cables in order to minimise the noise interference at high switching frequencies. According to state of incoming gate signal (high or low), isolated gate drive IC supplies either $+22 \mathrm{~V}$ to turn-on or $-3.1 \mathrm{~V}$ to turn-off an individual SiC MOSFET. In- 


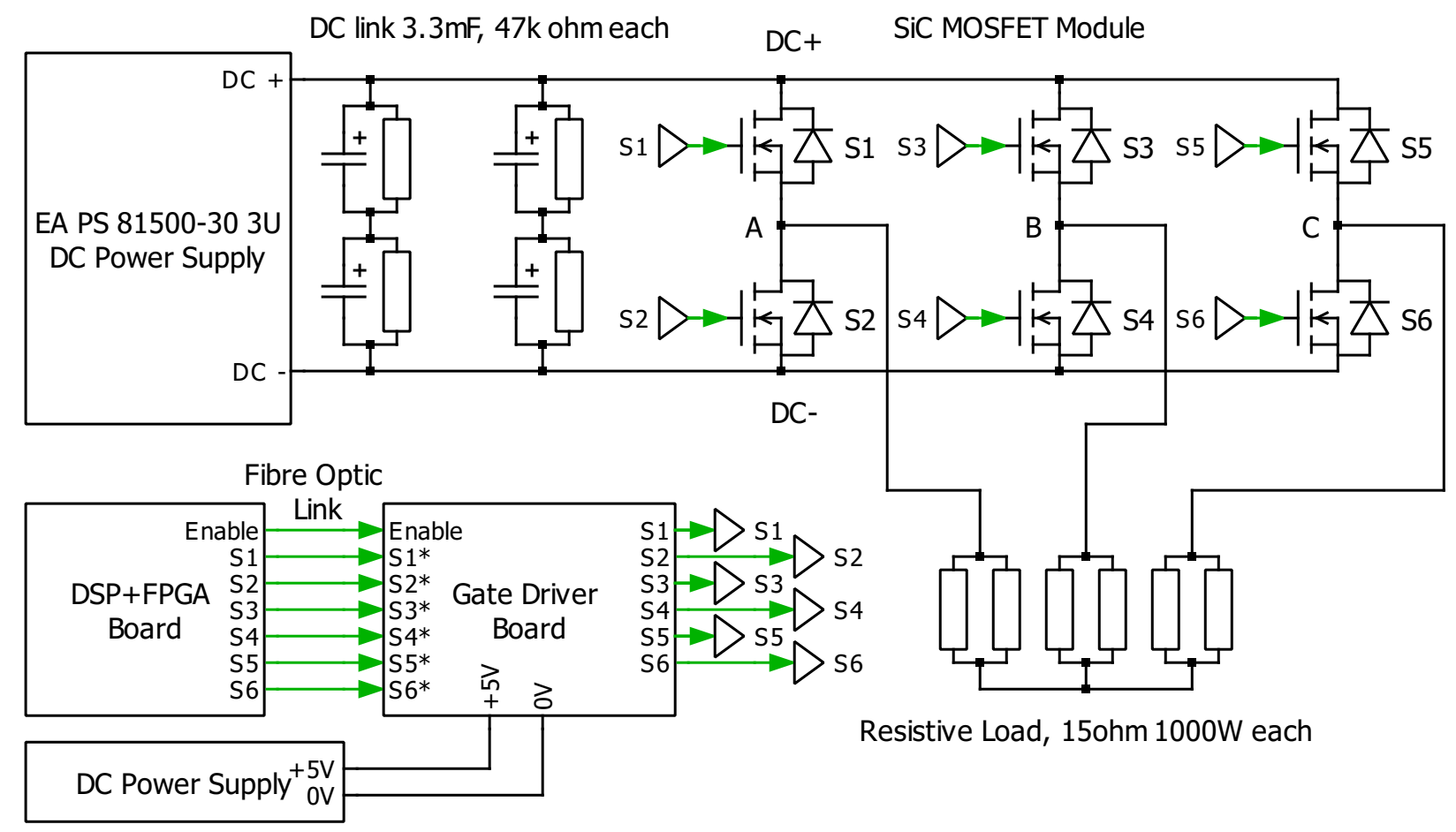

Figure 3: Test setup

put DC link voltage is $540 \mathrm{~V}$ fixed input that represents DC bus in an avionic system and the converter test at full load $(6 \mathrm{~kW})$ and half load $(3 \mathrm{~kW})$ conditions. Output phase-to-neutral RMS voltage is set to $115 \mathrm{~V}$ with $50 \mathrm{~Hz}$ fundamental frequency.

\section{Experimental Results}

Testing of converter started with half load at $5 \mathrm{kHz}$ switching frequency and continued with $20,40,60,80$ and $100 \mathrm{kHz}$ switching frequencies respectively. For each switching frequency condition, the DC power supply voltage and current, and the load voltages and currents are measured in order to observe overall performance of the system. Additional to this, the gate-source voltage $V_{G S}$ and drain-source voltage $V_{D S}$ waveforms of switch $S_{1}$ are recorded to assess the performance of SiC MOSFET under different load and switching frequency conditions.

\subsection{MOSFET Switching Performance}

Turn-on and turn-off switching performance of MOSFET S1 in the module is assessed at different switching frequency conditions and turn-on and turn-off switching results are presented with gate-source voltage $V_{G S}$ and drain-source voltage $V_{D S}$ waveforms in Figure $6 \mathrm{a}$ and $6 \mathrm{~b}$ respectively.

Experimental results show that turn-on time of S1 is less than 60ns under all different switching frequency conditions. Turn-on time increases from $35 \mathrm{~ns}$ to $55 \mathrm{~ns}$ as the switching frequency is increased from $5 \mathrm{kHz}$ to $100 \mathrm{kHz}$. Under all switching frequency conditions, turn-on duration stays within

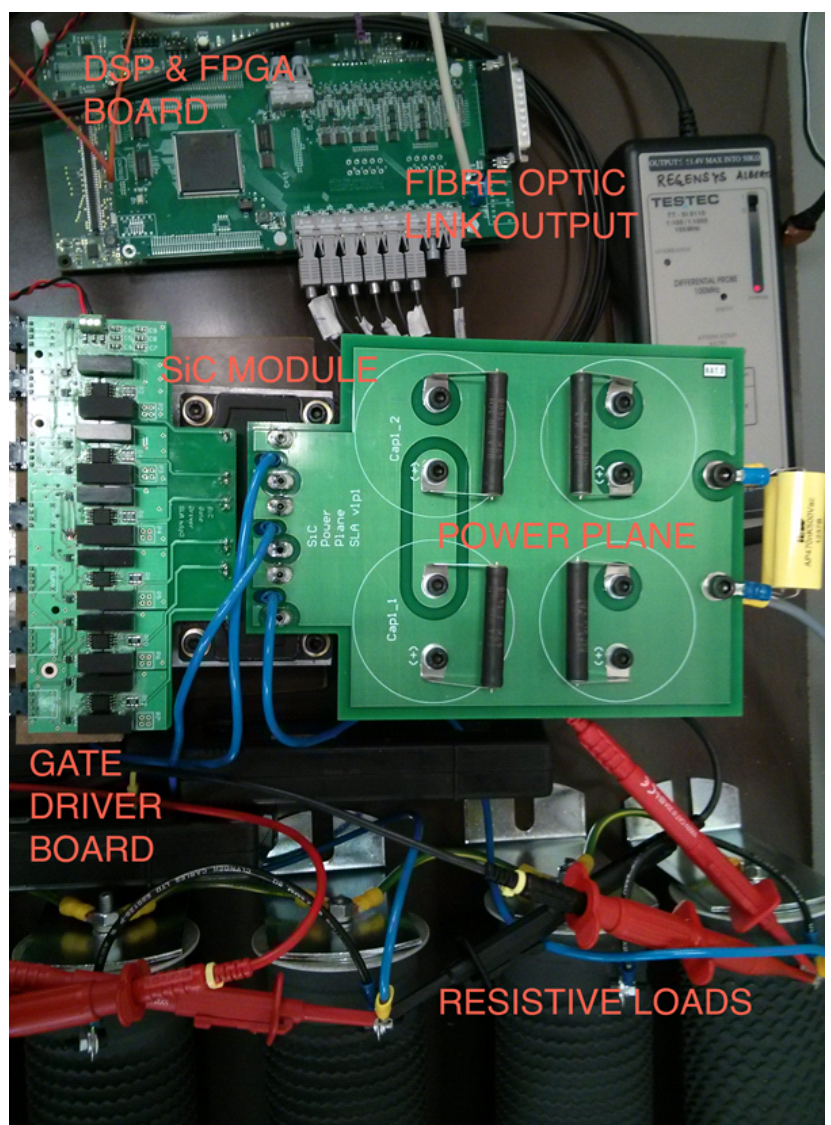

Figure 4: Experimental test setup 
expected range and is significantly shorter than turn-on time of a conventional $1200 \mathrm{~V}$ Si IGBT at given load conditions. Turn-off time of SiC MOSFET is also under 60ns under all switching frequency conditions. In parallel to turn-on performance, turn-off time increases from $30 \mathrm{~ns}$ to $60 \mathrm{~ns}$ as the switching frequency is increased from $5 \mathrm{kHz}$ to $100 \mathrm{kHz}$.

According to device datasheet in [13], forward voltage drop of body diode is $3.5 \mathrm{~V}$ that is twice as forward voltage drop of a discrete $1200 \mathrm{~V} \mathrm{SiC} \mathrm{Schottky} \mathrm{diode} \mathrm{in} \mathrm{[14].} \mathrm{Dead-time} \mathrm{be-}$ tween top and bottom switch in each phase leg is set to 500ns during the experiments and the body diode of the complementary switch in the phase leg is in conduction during dead-time. The results show that dead-time value can be set to smaller values in order to decrease the conduction time of body diode of MOSFET that will lead to increase in system efficiency.

\subsection{Output Current}

The converter is tested at different switching frequencies with resistive and inductive load conditions. Current waveforms of phase A at full resistive load condition with 5,60 and $100 \mathrm{kHz}$ switching frequencies are presented in Figure 5. The results show that phase current is discontinuous at $5 \mathrm{kHz}$ and as the switching frequency increases, phase current becomes continuous due to leakage inductance at the resistive loads and phase cables. Measured leakage inductance at each phase is approximately $90 \mu \mathrm{H}$.

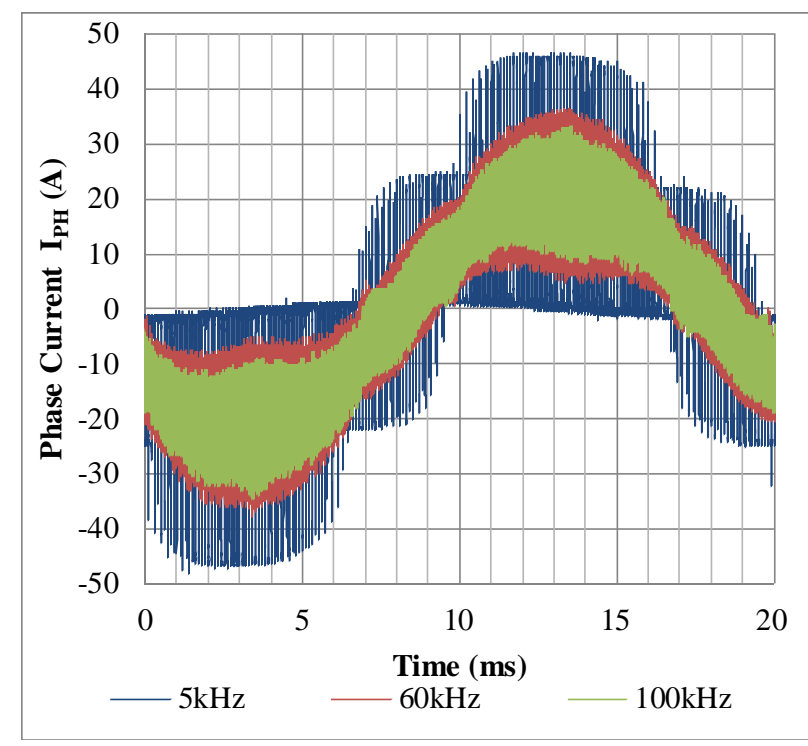

Figure 5: Output phase A current waveforms for different switching frequencies at full load.

Output current waveforms for resistive load at 100kHz switching frequency and for inductive load at $5 \mathrm{kHz}$ and $100 \mathrm{kHz}$ switching frequencies are presented in Figure $7 \mathrm{a}$ and $7 \mathrm{~b}$ respectively. Inductive load provides continuous phase current at low switching frequencies. In Figure $7 \mathrm{~b}$, current ripple at $100 \mathrm{kHz}$ is much smaller than the ripple at $5 \mathrm{kHz}$ but high current spikes occur during deadtime events and these events

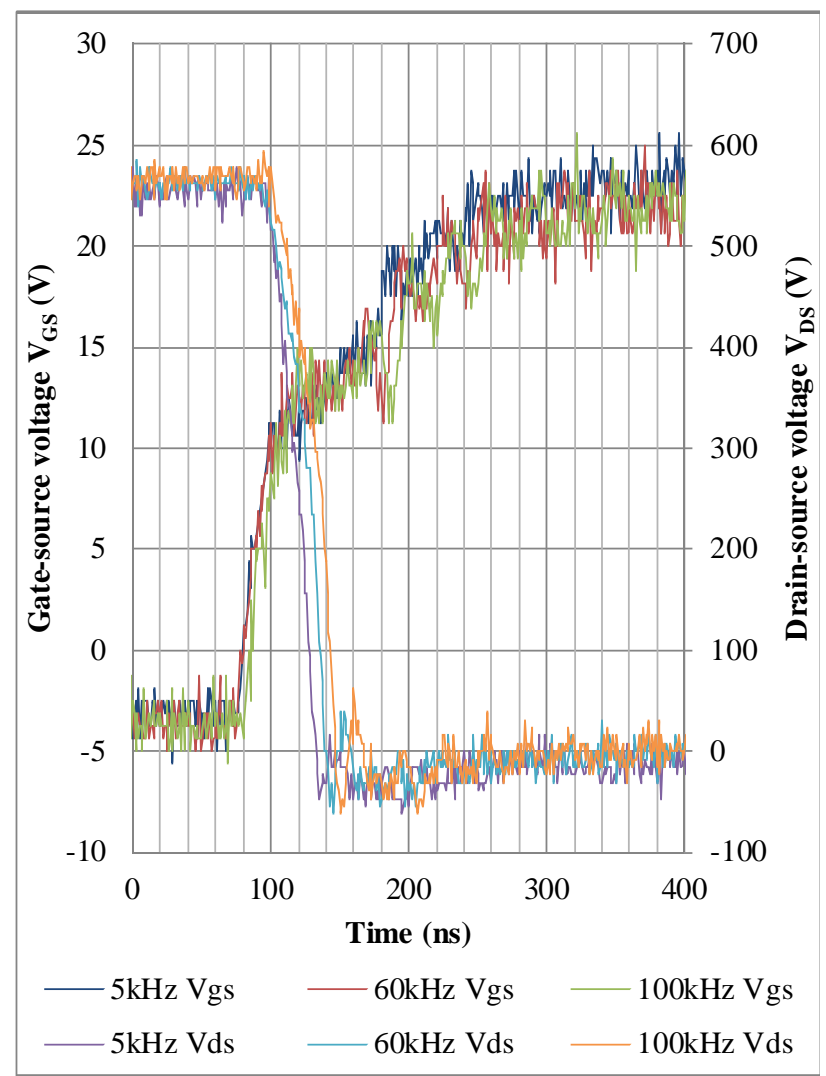

(a)

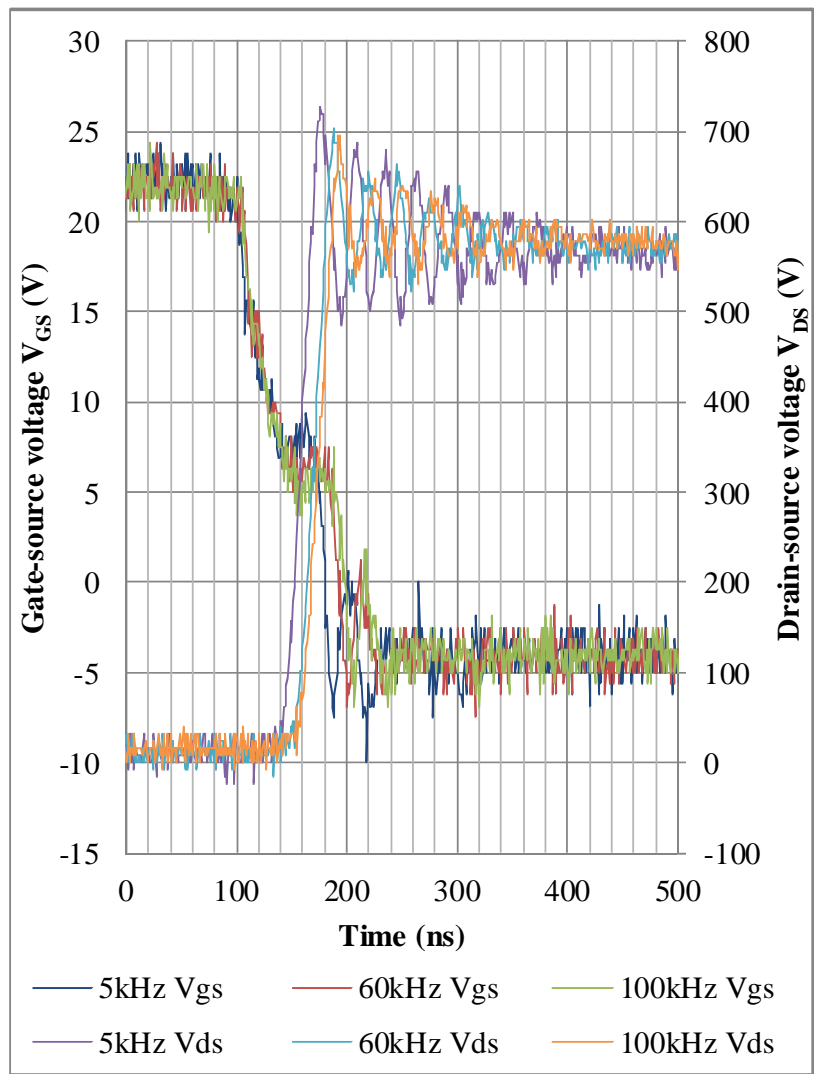

(b)

Figure 6: Switching transient waveforms for different switching frequencies at full load: (a) turn-on and (b) turn-off 


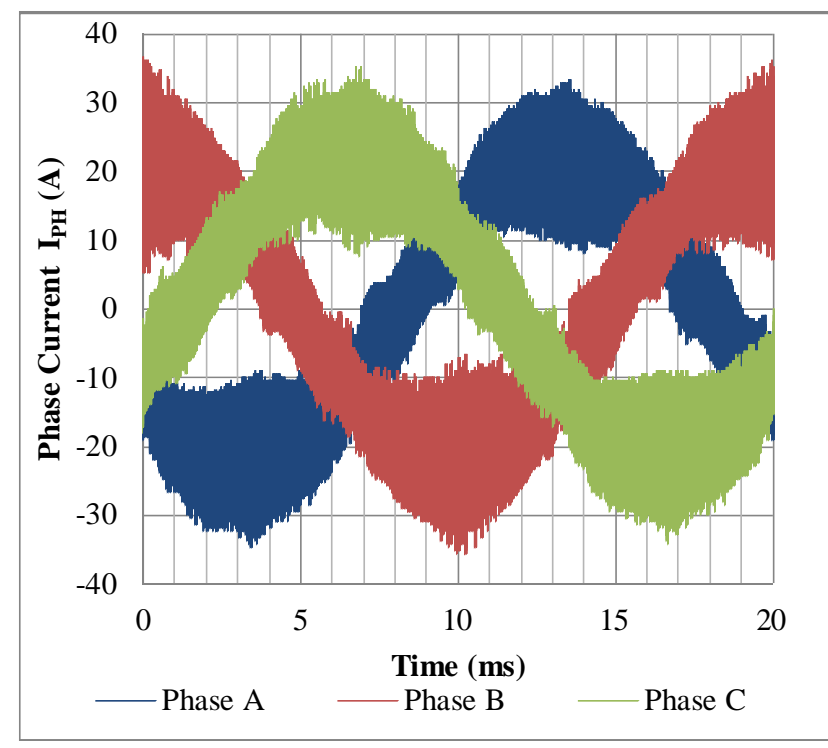

(a)

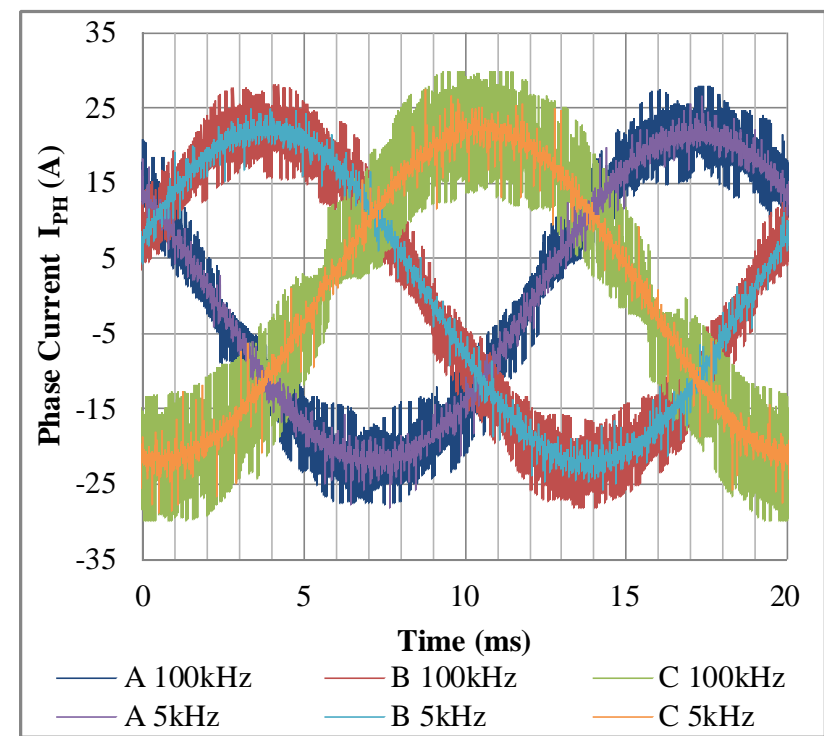

(b)

Figure 7: Output current waveforms for different switching frequencies with : (a) resistive load and (b) inductive load

introduce noise to output current waveform. Both Figure 7a and $7 \mathrm{~b}$ proves that the power module can successfully operate with $6 \mathrm{~kW}$ resistive and inductive load conditions between $5 \mathrm{kHz}$ and $100 \mathrm{kHz}$ switching frequencies.

Efficiency of the converter is measured at $6 \mathrm{~kW}$ output power for different switching frequencies. Efficiency curve is presented in Figure 8. The efficiency curve shows that SiC module maintains high efficiency between $5 \mathrm{kHz}$ and $100 \mathrm{kHz}$. This high performance of the module at high switching frequencies is beneficial for achieving high power density by reducing size of passive components.

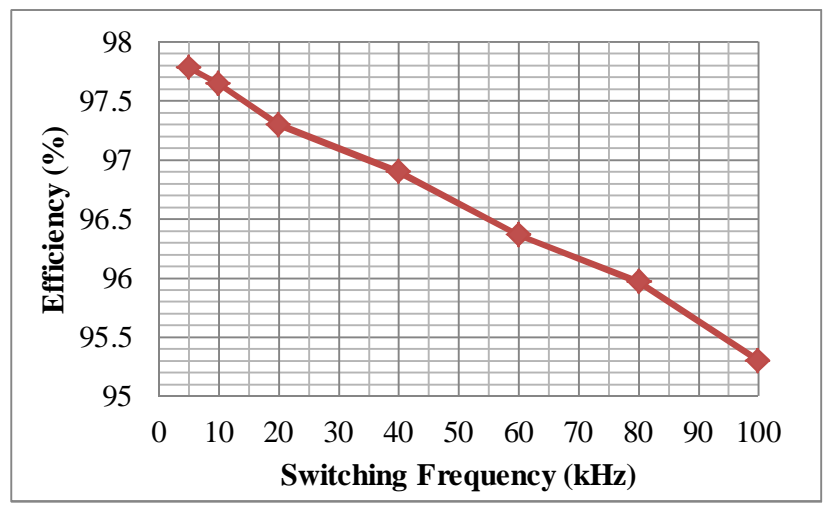

Figure 8: Efficiency of the converter at $6 \mathrm{~kW}$ output power for different switching frequencies

\section{Conclusion}

In this paper, thermo-mechanical design, test setup, test approach and experimental results of a three-phase two-level $\mathrm{SiC}$ power module are presented. Thermo-mechanical design is based on minimising weight of the module while maintaining maximum reliability for avionic applications. A flexible test setup is designed in order to test the module in a power converter under different load and switching frequency conditions. Experimental results show that $\mathrm{SiC}$ power module can successfully operate under resistive and inductive loads up to $6 \mathrm{~kW}$ output power between $5 \mathrm{kHz}$ and $100 \mathrm{kHz}$ switching frequencies. The converter maintains high efficiency at high switching frequencies due to superior switching and conduction properties of $\mathrm{SiC}$ devices. The module can be used to design high frequency, high power density converters with high efficiency in avionic systems.

\section{Acknowledgements}

Authors would like to thank European Union Clean Sky JTI programme for funding of Robust Silicon Carbide Technology for Aerospace DC-DC Conversion (RoSiC) project.

\section{References}

[1] B. Baliga, "Trends in power semiconductor devices," IEEE Transactions on Electron Devices, vol. 43, no. 10, pp. 1717-1731, 1996.

[2] C. Weitzel, J. Palmour, C. Carter, K. Moore, K. Nordquist, S. Allen, C. Thero, and M. Bhatnagar, "Silicon carbide high-power devices," IEEE Transactions on Electron Devices, vol. 43, no. 10, pp. 1732-1741, 1996.

[3] J. Millan, P. Godignon, X. Perpinya, A. Perez-Tomas, and J. Rebollo, "A Survey of Wide Band Gap Power Semiconductor Devices," IEEE Transactions on Power Electronics, no. c, pp. 1-1, 2013.

[4] T. Santini, M. Sebastien, M. Florent, L.-V. Phung, and B. Allard, "Gate oxide reliability assessment of a $\mathrm{SiC}$ 
MOSFET for high temperature aeronautic applications," in 2013 IEEE ECCE Asia Downunder, pp. 385-391, IEEE, June 2013.

[5] A. Castellazzi, T. Funaki, T. Kimoto, and T. Hikihara, "Thermal instability effects in SiC Power MOSFETs," Microelectronics Reliability, vol. 52, pp. 2414-2419, Sept. 2012.

[6] S. Safari, A. Castellazzi, and P. Wheeler, "Experimental and Analytical Performance Evaluation of SiC Power Devices in Matrix Converter," IEEE Transactions on Power Electronics, no. c, pp. 1-1, 2013.

[7] Z. Chen, Y. Yao, D. Boroyevich, K. Ngo, P. Mattavelli, and K. Rajashekara, "A 1200 V, 60 A SiC MOSFET Multi-Chip Phase-Leg Module for High-Temperature, High-Frequency Applications," IEEE Transactions on Power Electronics, no. c, pp. 1-1, 2013.

[8] S. Lefebvre, M. Berkani, Z. Khatir, A. Ibrahim, and A. Bouzourene, "Investigation of $1.2 \mathrm{kV}$ investigation of SiC MOSFETs for aeronautics applications," in 2013 15th European Conference on Power Electronics and Applications (EPE), pp. 1-9, IEEE, Sept. 2013.

[9] B. Cougo, H. Schneider, and T. Meynard, "Accurate switching energy estimation of wide bandgap devices used in converters for aircraft applications," in 2013 15th European Conference on Power Electronics and Applications (EPE), pp. 1-10, IEEE, Sept. 2013.

[10] R. A. Wood and T. E. Salem, "Evaluation of a 1200V, 800-A All-SiC Dual Module," IEEE Transactions on Power Electronics, vol. 26, pp. 2504-2511, Sept. 2011.

[11] Z. Liang, P. Ning, and F. Wang, "Development of Advanced All-SiC Power Modules," IEEE Transactions on Power Electronics, vol. 29, no. 5, pp. 1-1, 2013.

[12] R. A. Wood and T. E. Salem, "Long-term operation and reliability study of a 1200-V, $880-A$ all-SiC dual module," International Symposium on Power Electronics Power Electronics, Electrical Drives, Automation and Motion, pp. 1520-1525, June 2012.

[13] CREE Inc, “CPMF-1200-S080B SiC MOSFET," Datasheet, 2013.

[14] CREE Inc, “C2D20120D SiC Diode,” Datasheet, 2013. 